\title{
SMART CITIES: UNDER-GRIDDING THE SUSTAINABILITY OF CITY-DISTRICTS AS ENERGY EFFICIENT-LOW CARBON ZONES
}

\author{
MARK DEAKIN \& ALASDAIR REID
}

\begin{abstract}
This paper reviews the literature on smart cities. Offering a critical synthesis of the material, it advances a Triple Helix inspired account of smart cities as future internet-based developments. In particular, as future internet-based developments covering the digital infrastructures, data management systems, renewable energies and cloud computing of a regional innovation in the Internet of Things (IoT). More specifically, as a regional innovation in the IOT that covers the morphology of urban extensions, infill and mass retrofits, which smart cities call for the development of. Focusing on the metrics of mass retrofit proposals, the paper also serves to demonstrate how the urban morphology of such regional innovations matter in the sense they tell us that being aware of the considerable energy savings and $\mathrm{CO}_{2}$ reductions, which loTs offer cities to be smart, is not enough. Not enough, because without knowing whether the costs and benefits under-gridding the sustainability of city-districts are shared equally, it is impossible to say if the $65 \%$ energy saving and $78 \%$ reduction in $\mathrm{CO}_{2}$, attributed to the data collection, information processing and smart (micro) grids of mass retrofits is socially just. The paper suggests that in order to verify this, it is necessary for smart cities to first baseline the social-demographic structure of retrofit proposals. Then draw upon the environmental profile this evaluation generates to assess whether the regional innovation creates the wealth needed to under-grid the sustainability of city-districts. In particular, under-grid the sustainability of city-districts as the energy efficient-low carbon zones of an inclusive growth strategy seen to be socially just. Seen to be socially just, because the costs and benefits underlying the 1.5 hectare ecological footprint that surfaces from this regional innovation are equally appropriated as the proceeds of a wealth creation, which contributes to the resilience of city-districts as energy efficient-low carbon zones. As energy efficient-low carbon zones, whose inclusive growth strategy also emerges as a post-carbon economy claiming to be climate neutral.
\end{abstract}

Keywords: smart cities, legacy systems, digital infrastructures, data management systems, renewable energies, internet of things, regional innovation, urban morphology, under-gridding, city-districts, sustainability, mass retrofit, energy efficient-low carbon zones.

\section{Introduction}

This paper shall summarise the findings of a literature review on smart cities and go on to provide an overview of the critical insights it offers into the metrics of a future internet-based development promoted by Manchester, Amsterdam, Malmo and Barcelona to under-grid the sustainability of city-districts. That type of sustainable city-district, which London, Stockholm, Rome, Vienna and Hamburg are also in the process of developing as energy efficient-low carbon zones.

Against this backdrop, the paper goes on to examine the digital infrastructures, data management systems and renewable energies underpinning the mass retrofitting of Hackbridge (a suburb in the London Borough of Sutton) as a city-district. In particular, as the city-district whose digital infrastructures and data management systems support future internet-based developments on the grounds the cloud computing and IoT they found, constitute the governances of a smart, sustainable and inclusive growth strategy. Constitute the governances of a growth strategy that is not only smart in getting the cloud computing of an IoT to support future internet-based developments, which under-grid the sustainability of city-districts as energy efficient-low carbon zones, but that also holds out the prospect of creating wealth from a regional innovation, which is inclusive.

\section{Literature review}

Reporting on the findings of a bibliometric analysis, de Jong et al. (2015:34) state:

“...the category 'smart city' has proven particularly popular not only among adopting cities, but also among large engineering firms, because it offers concrete innovation and investment opportunities for physical urban and infrastructure development. It promotes engineering system solutions".

Deakin $(2011,2013,2014)$ and Deakin et al. (2012a, 2012b, 2014) also examine the popularity of the "concrete innovation and investment opportunities" smart cities offer in terms of "physical and infrastructural 
development". Here, the analysis progresses not by way of a bibliometric analysis, but literature review and critical synthesis of the emerging accounts of smart cities this captures. In particular, that literature, which accounts for the development of smart cities by way of Ranking Systems and through Future Internet and Triple Helix models of them as regional innovations.

This reveals that for Giffinger et al. (2008) Ranking Systems offer a means by which cities can "out-smart" one another in terms of marketing the innovative qualities of smart cities. In this account, standard ranking procedures are recast by prefixing the word "smart" to cities, which out-perform one another and by attributing terms such as economy, people, governance, mobility, environment and quality of life to market the innovative qualities that constitute smart cities. Schaffers et al. (2011) suggest something to the opposite and claim the marketing of these innovative qualities rest not so much on the physical existence of such attributes, but instead on the digital infrastructures that underpin smart cities as Future Internet developments. Unlike either Ranking Systems, or Future Internet accounts, the Triple Helix model of smart cities suggests that it is the intellectual capital of these digital infrastructures, which is smart in exploiting the opportunities, which data management systems offer cities to govern the process of wealth creation future internet-based developments generate. In particular, smart in exploiting the opportunities, which these digital infrastructures and data management systems offer cities to create wealth from future internet-based developments that generate a regional innovation (Leydesdorff and Deakin 2011, Deakin and Leydesdorff, 2013 and Deakin, 2014). Contrary to what either the Ranking Systems or Future Internet accounts claim, the Triple Helix model suggests that it is the reflexive instability of the intellectual capital tied up in the digital infrastructures, data management system and renewable energies of this regional innovation, which is of particular interest. For what the intellectual capital of such digital infrastructures offers is the prospect of cities becoming smart in developing data management systems, by way of cloud computing and though an IoT, which not only stabilises the process of wealth creation, but that also serves to consolidate this as the renewable energy of a regional innovation.

This is what distinguishes the Ranking Systems, Future Internet and Triple Helix accounts of smart cities from one another and serves to put critical distance between them. For while each of them accepts the need for some form of Ranking System, the Future Internet account is content for universities and industry to merely participate in the development of such attributes, whereas the Triple Helix model sees the governance of the wealth created from future internet-based developments as critical. As critical in the sense, which future internet-based developments not only underpin digital infrastructures, but also support the data management systems, which stabilise the wealth that is created from the attributes of such a regional innovation. In particular, from that process of wealth creation, which reflects the popularity of the engineering solutions these regional innovations also promote as renewable energies.

In contrast to what de Jong et al. (2015:34) suggest, rather than shifting "attention away from environmental conceptions", this Triple Helix inspired model of smart cities as future internet-based developments, does just the opposite. Just the opposite in the sense that it offers smart cities a model of future internet-based developments, which not only underpins the digital infrastructures they design but that also supports the data management systems they layout as those attributes, which create wealth from the renewable energies of a regional innovation. From the renewable energies of a regional innovation that is set within the cloud computing of an IoT and whose data collection, information processing and smart (micro) grids, constitute an urban morphology, which is able to stabilise the value of those energy saving and carbon reductions such environmentally sustainable solutions engineer (Hirst et al. 2012).

This paper shall suggest that it is the future internet-based developments, which in de Jong et al's. (2015:34) words, now brings the digital infrastructures of data management systems "centre stage". That is to say, makes the digital infrastructures of data management systems even more marked for the simple reason it is the attributes of these future internet-based developments, which lie at the centre of the attempts currently being made by universities, industry and governments, to recast the models of urban morphology. Models the likes of Ratti et al. (2005), Salat (2009), Bourdic and Salat (2012), and Bourdic et al. (2012) offer and that are currently being recast to capture the digital infrastructure of a data management system, which are able to leverage renewable energies as a process of regional innovation. As that process of regional innovation, which such environmentally sustainable solutions engineer to stabilise wealth creation.

Keeping this contention firmly in mind, what follows shall account for how the digital infrastructures of data management systems draw upon future internet-based developments as the cloud computing of an loT able to stabilise the creation of wealth from renewable energies and be that very "thing", which brings this process of regional innovation fill circle. In that sense, offer an account of smart cities, which does not rely on either 
the markets of Ranking Systems, or a Future Internet attribution of them as digital infrastructures, but the data management system these markets attribute to future internet-based developments. In particular, which these markets attribute to future internet developments as the cloud-based computing of an loT whose data collection, information processing and smart (micro) grids, constitute an urban morphology that is able to leverage renewable energies as a regional innovation. In particular, as a regional innovation able to stabilise the creation of wealth from the environmentally sustainable solutions this engineers as "concrete investment opportunities" (de Jong et al. 2015:34).

With this in mind, the rest of this paper shall account for smart cities by capturing the metrics that govern the intellectual capital of future internet-based developments as markets and which attribute them to the digital infrastructures of data management systems. Then go on to report on the renewable energies that stabilise the creation of wealth from this regional innovation as the cloud computing of an IoT, which allows the urban morphology of city-districts to under-grid the sustainability of those "concrete investment opportunities", smart cities engineer. Which they engineer as city-districts to under-grid the sustainability of "investment opportunities" as energy efficient-low carbon zones able to stabilise the value of the wealth created. This shall also provide the opportunity to extend the principal component-based grid analysis of future internet developments developed by Hirst et al. (2012) and Kourtit et al. (2013). Extend it into this process of regional innovation and demonstrate how the metrics of these digital infrastructures, data management systems and renewable energies, compute as an IoT, whose morphological structure is able to under-grid the sustainability of city-districts as the energy efficient-low carbon zones of an inclusive growth strategy.

\section{Capturing the metrics of smart cities}

The metrics governing the intellectual capital of future-internet based developments are found in the Triple Helix model of smart cities advanced by Lombardi et al. (2012) Lombardi and Giordano (2012), Hirst et al. (2012) and Kourtit et al. (2013). This Triple Helix model gets beyond the empiricism of the Ranking Systems and collaborative logic of Future Internet accounts and achieves this by allowing the intellectual capital of cities, to be rendered smart by pioneering the development of future internet-based technologies. In pioneering developments, which Caragliu et al. (2013) note, are not only successful in supporting the types of positive associations future internet-based technologies already have with smart cities, but that deep restructuring of the ICT sector, which also allows these digital infrastructures to include energy, water and waste as data management systems.

This deep restructuring of digital infrastructures, as the data management systems of a regional innovation in the ICT, energy, water and waste sectors, is a development Lombardi et al. (2012) also draw attention to. It is a matter Hirst et al. (2012) and Lazaroiu and Roscia (2012) highlight the growing significance of in relation to the European Commission's (ECs) Smart, Sustainable and Inclusive Growth Strategy and in terms of how these regional innovations support the Smart Cities and Communities Programme. ${ }^{1}$

The metrics associated with this deep restructuring of the ICT, energy, water and waste sectors is a matter Hirst et al. (2012) explore further. ${ }^{2}$ They offer a principle component-based analysis as a grid for modelling the future internet-based developments of smart cities. This is set out in Figure 1 and captures the findings of the research conducted by Hirst et al. (2012) to capture instances of where future internet-based developments have been smart in "under-gridding" the deep restructuring of cities ICT and energy sectors. In particular, in under-gridding the design of digital infrastructures as the data management systems of renewable energies that combine in the cloud computing of an loT, which is able to support a smart, sustainable and inclusive growth. Figure 1 also serves to highlight the developments that underpin the ICTs of these digital infrastructures and which support the data management systems of renewable energies in the cloud computing and IoT of smart buildings. This also reveals the object of this under-gridding to be the sustainable and inclusive growth of city-districts as energy efficient-low carbon zones. Kourtit et al. (2013) report on the performance of future internet-based developments, as well as the digital infrastructures and data management system smart cities engineer (see also Komninos et al. 2013; Komninos, 2014 and Deakin, 2014).

What follows shall concentrate on the development of these digital infrastructures as the data management systems of renewable energies. That is as the digital infrastructures and data management systems of renewable energies in the cloud computing of an loT servicing smart buildings (see Figure 1). This identifies

\footnotetext{
${ }^{1}$ http://eu-smartcities.eu/content/fp7-smart-cities-and-communities-call-proposals-now-open

2 http://ec.europa.eu/research/regions/index en.cfm?pg=smart specialisation
} 
the pioneers of Europe's Smart, Sustainable and Inclusive Growth Strategy to be the cities of Manchester, Amsterdam, Malmo and Barcelona. It also illustrates how these smart cities have begun to construct sustainable and inclusive growth strategies around regional innovations in the ICT and energy sectors. This illustration also serves to highlight the components of this growth strategy. In particular, the digital infrastructures, data management systems, renewable energy, smart buildings and smart transport components of this regional innovation.

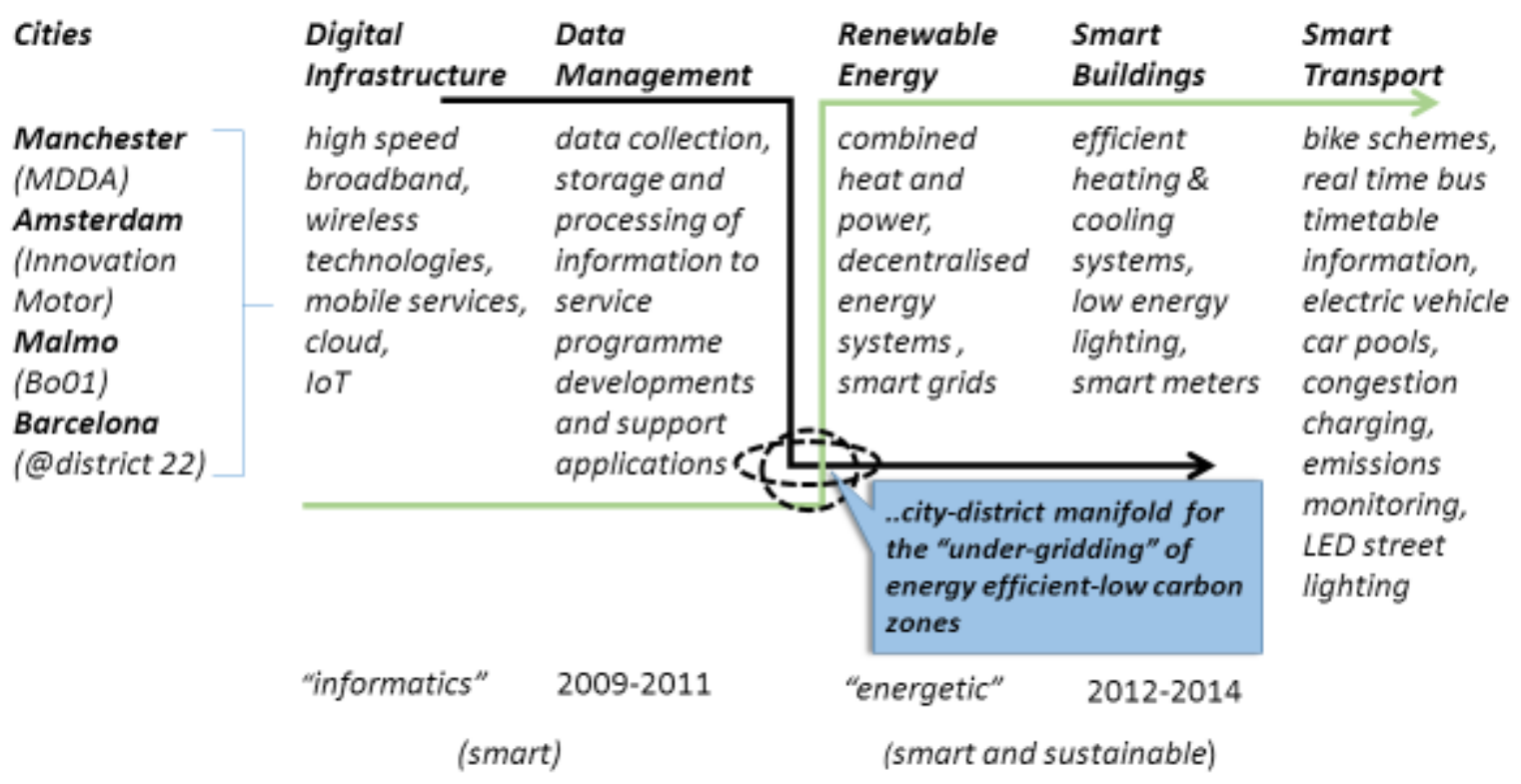

Figure 1. A principle component-based grid of smart city developments. Source: Adapted from Hirst et al. (2012).

This account of smart cities also goes some way to trace the principle legacy systems of these future internet-based developments: namely the ICT and energy sectors and the modulation of their growth as a "broadband" of digital infrastructure, data management, renewable energy, building and transport applications. With the ICT sector, attention focuses on the smart growth of the first two components (digital infrastructures and data management systems) and in the cloud computing of an IoT. In the energy sector, the emphasis is on the sustainable and inclusive growth of renewable energies in buildings.

As Zhang et al. (2013) and Zhang (2016), also note, it is these top-level issues (ICT and energy) that bottomout in the digital infrastructures, data management systems and renewable energies of what they refer to as sustainable urban development. Here the drivers of smart growth are issues such as high-speed broadband, data collection and storage. Issues to do with the cloud computing and an loT, that bottom-out in the energy sector as the smart grids of renewable energies and which are found in the metering of smart buildings. Figure 1 shows these issues as those to do with combined heat and power, efficient heating and cooling measures. Consequently, what follows shall concentrate on the networking of these digital infrastructures and data management systems as regional innovations in the renewable energies of city-districts, which under-grid the sustainability of energy efficient-low carbon zones.

Those smart cities pioneering this regional innovation are listed in Table 1. This shows the city-districts of Mitte Altone, Hafen City, Aspern Lakeside, Spina 4+, Via dei Cerchi, the Royal Sea Port, Vallbona and Hackbridge, as the pioneers of such regional innovations (see Table 1). Table 1 also illustrates the tons of $\mathrm{CO}_{2}$ emissions per capita for these city-districts and compares them to the parent city and national equivalents. Figure 2 shows the performance of these city-districts in terms of energy savings and as $\mathrm{CO}_{2}$ emission reductions.

In classifying the morphology of the city-districts as urban extensions (UE), urban infill (UI) and urban retrofits (UR), the regional innovation they uphold the standards of, forecast savings and reductions in excess of those laid down by the EC. As the standard-bearers of sustainable and inclusive growth and 
pioneers of both the energy saving and $\mathrm{CO}_{2}$ emission reductions, these city-districts are at the forefront of such developments. Indeed, they are so advanced, as to offer the prospect of a smart dividend for the development of sustainable city-districts set within neighbourhood communities.

\begin{tabular}{|lccc|}
\hline Hackbridge, London & District & City & Nation \\
\hline Vallbona, Barcelona & 1.2 & 5.8 & 8.5 \\
\hline Royal Sea Port, Stockholm & 1.5 & 2.5 & 6.8 \\
\hline Via dei Cerchi, Rome & 1.5 & 3.5 & 6.9 \\
\hline Spina 4+, Turin & 2.75 & 3.5 & 7.2 \\
\hline Aspern Lake Side, Vienna & 2.75 & 6.0 & 7.2 \\
\hline Hafen City, Hamburg & $(5.0)$ & 5.0 & 8.5 \\
\hline Mitte Altone, Hamburg & 5.75 & 9.0 & 9.6 \\
\hline
\end{tabular}

Table 1. Tons of $\mathrm{CO}_{2}$ Emissions per Capita.

Source: Brandt et al. (2014).

Note: the figures in parentheses are estimates.

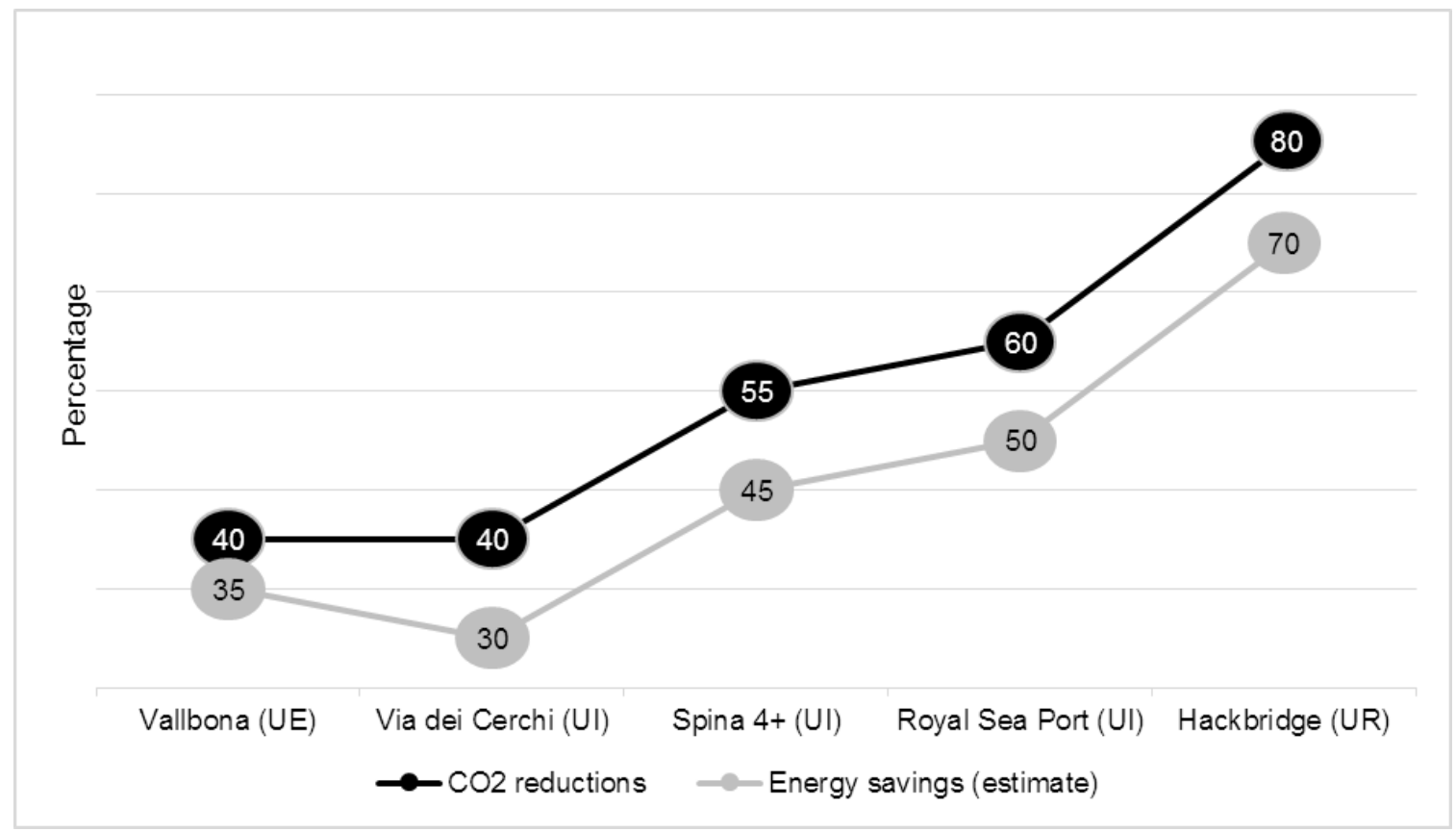

Figure 2. Performance-based criteria.

Source: Brandt et al. (2014).

The remainder of this paper shall address the web-based data collection and information processing applications of that mass retrofit, which is underway in Hackbridge (a suburb in the London Borough of Sutton). In particular, the levels of energy saving and $\mathrm{CO}_{2}$ reduction arising from the cloud computing and IoT of the smart, sustainable and inclusive growth strategy this city-district develops. This is because the urban morphology of this city-district not only offers a sustainable and inclusive growth strategy that undergrids an energy efficient-low carbon zone, but prospect of also creating wealth from a regional innovation whose post-carbon economy can claim to be climate neutral. That is, a regional innovation, whose process of wealth creation complies not just with the energy saving and $\mathrm{CO}_{2}$ reduction targets, which are set by the EC, but level of environmental sustainability the IPPC (2015) define as socially significant because the postcarbon economy, which this develops is climate neutral. 


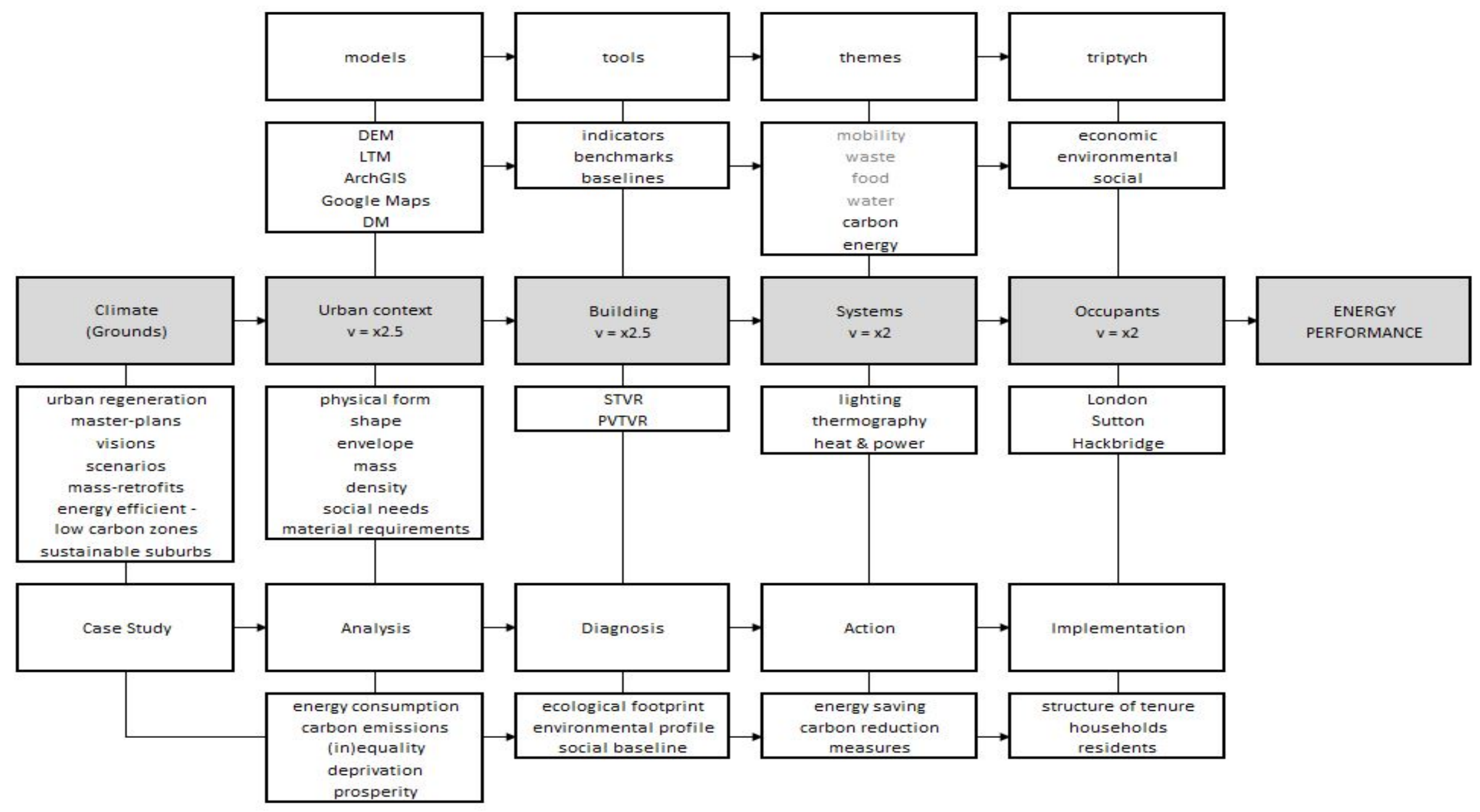

Figure 3. Adaptation of the standard morphological model.

Source: Deakin et al. (2014). 
This in turn offers the opportunity to extend this principal component-based grid analysis of smart cities, into the urban morphology of regional innovation and demonstrate how the metrics of these digital infrastructures, data management systems and renewable energies serve to engineer a cloud-based loT capable of under-gridding the sustainability of city-districts as energy efficient-low carbon zones (see Figure 3). In particular, as the energy efficient-low carbon zones of an inclusive growth strategy, whose savings and reductions can claim to not just be energy efficient, or low carbon, but also sufficiently resilient for the built environment to prosper from as a climate neutral adaptation strategy.

\section{Extending the Principal Component-based Grid Analysis}

Figure 3 builds upon the standard morphologic model advanced by Ratti et al. (2005), Salat (2009), Bourdic and Salat (2012), and Bourdic et al. (2012). It also illustrates the Digital Elevation Modelling (DEM) underpinning the Lighting and Thermal Method (LTM), adopted to compute the geometry of the urban morphology and support this with a 3D context-specific rendering of the material. The next column shows the tools available to indicate, benchmark and baseline the "surface-to-volume ratio" (STVR) and "passivevolume-to-total-volume ratio" (PVTVR) of the blocks, neighbourhoods and city-districts under examination. This in turn draws attention to the infrastructural themes and management issues (energy, $\mathrm{CO}_{2}$, water and mobility), associated with the power, heating and lighting systems of mass retrofit proposals.

The final column highlights the triptych, vis-à-vis the social and environmental sustainability of those who occupy this city-district as energy efficient-low carbon zones. Under this lies a further level of case study analysis. This draws attention to the diagnosis, action and intervention of urban planners, architects, designers and building contractors and whose city-districts under-grid the sustainability of energy efficientlow carbon zones as part of an inclusive growth strategy. This model systematically integrates renewable energies into the heating and power systems of the retrofit proposal. In particular, it defines how the lighting and thermography of the heating and power systems set the baseline to assess the underperformance of buildings and evaluate possible improvements to their fabric. This translates into the STVR and PVTVR ratio for the baseline calculations. Such an assessment does not reduce performance to the social-demography of these baselines, but instead extends it onto an environmental profile, which supports the energy consumption and $\mathrm{CO}_{2}$ emissions of those occupying the city-district. This dispenses with mere headcounts and assembles the material necessary to not just collect data, but also process the information these applications need to assess the status of city-districts as energy efficient-low carbon zones.

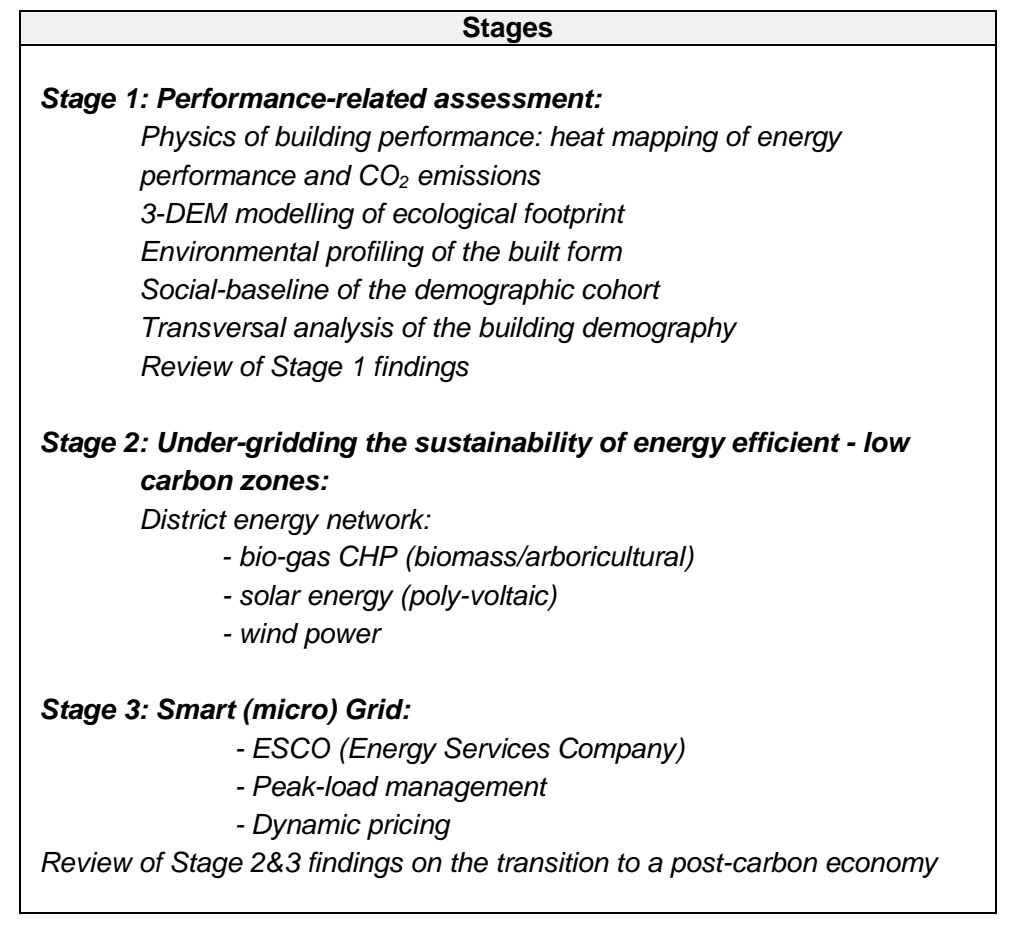

Table 2. Protocol for under-gridding the sustainability of the mass retrofit proposal. Source: Adapted from London Borough of Sutton and Bioregional (2012). 


\section{Under-gridding the Sustainability of a City-District}

Table 2 captures the protocol for under-gridding the sustainability of this city district as an energy efficientlow carbon zone. It outlines the key components of this case study in under-gridding the sustainability of a city district. As an exercise, it is unique in representing the environmental profile of the energy efficient-low carbon zone.

Table 3 illustrates the bottom-line sustainability of this environmental profile in terms of what such a webbased data collection and information-processing application contribute to the status of city-districts as energy efficient-low carbon zones. For each of the households within the environmental profile of this energy efficient-low carbon zone, it shows a:

- 3-ton reduction in the levels of $\mathrm{CO}_{2}$ emissions, gained from the energetics of this smart city development;

- $\quad$ further 3-ton reduction of $\mathrm{CO}_{2}$ emission results from the informatics of this under-gridding and as a process of sustainable growth, this produces a total projected emission reduction of 6 tons per annum;

- $\quad 78 \%$ overall reduction in $\mathrm{CO}_{2}$ emissions that meets the IPCC standards of climate neutrality and level of $\mathrm{CO}_{2}$ emissions which brings the ecological footprint for housing in the residential property sector down towards 1.5 hectares of bio-productive land. That share of world productive land, which contributes to the growth of cities that is sustainable in the sense, which the development of Hackbridge has no adverse impact on the levels of global warming.

The metrics of this integration (i.e. in the micro-grid of this energy efficient-low carbon zone) also gives rise to the prospect of further $\mathrm{CO}_{2}$ emission reductions, vis-à-vis an extra $5 \%$, but for now the cloud computing of this IoT is not tried-and-tested and as a consequence, cannot be fully accounted for.

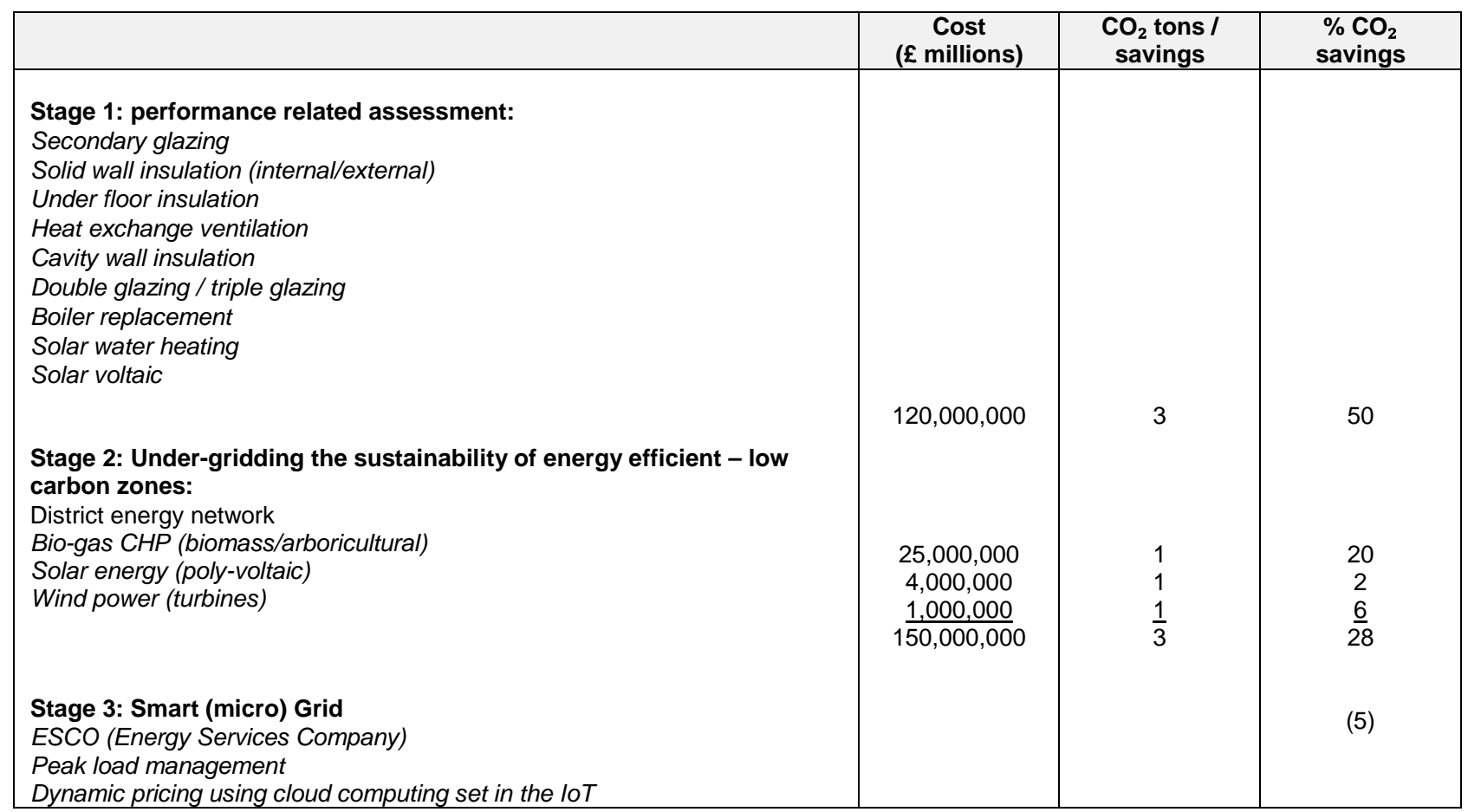

Table 3. Measures for baselining the sustainability of growth. Source: Adapted from London Borough of Sutton and Bioregional (2012).

Table 4 adopts the measures currently available for smart cities to baseline the sustainability of an inclusive growth strategy founded on post-carbon economy of climate neutrality. It shows the SVTR, PVTVR and empty space values and illustrates the mean energy consumption and $\mathrm{CO}_{2}$ emissions for Hackbridge, compared against London, Berlin and Paris. Salat's (2009) study area (the whole of the Paris metropolitan city-region) covers a much greater area than either the study undertaken by Ratti et al. (2005), or this paper's examination of Hackbridge. Here, the mean STVR is much higher than for the inner-city areas of 
London, Toulouse and Berlin. Table 5 relates these levels of energy consumption and rates of $\mathrm{CO}_{2}$ emissions to the STVR and PVTVR ratios in Hackbridge and goes on to cross-reference them against the structure of tenure found in the residential property sector, analysed by lower super output area (LSOA). These figures provide the data to calculate the energy savings and $\mathrm{CO}_{2}$ emission reductions for both respective retrofit options and inform on the improvements these generate (Table 6 and 7).

\begin{tabular}{|l|c|c|c|c|c|}
\cline { 2 - 5 } \multicolumn{1}{c|}{} & \multicolumn{3}{c|}{ Inner city district neighbourhood } & $\begin{array}{c}\text { Suburban city } \\
\text { district }\end{array}$ & $\begin{array}{c}\text { Metropolitan } \\
\text { city region }\end{array}$ \\
\cline { 2 - 6 } \multicolumn{1}{c|}{} & London & Toulouse & Berlin & Hackbridge & Paris \\
\hline Dimension of study area $\left(\mathrm{km}^{2}\right)$ & $\sim 0.03$ & $\sim 0.03$ & $\sim 0.03$ & $\sim 1.7$ & $\sim 105$ \\
\hline Ground floor area $\left(\mathrm{m}^{2}\right)$ & 89,663 & 64,368 & 55,978 & 91,778 & $67,000,000$ \\
\hline Un-built Area $\left(\mathrm{m}^{2}\right)$ & 70,377 & 95,632 & 104022 & 481,803 & $38,000,000$ \\
\hline Built volume $\left(\mathrm{m}^{3}\right)$ & $1,221,499$ & 966,768 & $1,042,199$ & 616,839 & $580,000,000$ \\
\hline Vertical surface $\left(\mathrm{m}^{2}\right)$ & 174,757 & 174,888 & 119,698 & 209,411 & \\
\hline STVR & 0.216 & 0.248 & 0.169 & 0.488 & \\
\hline PVTVR (\%) & 77 & 84 & 61 & 99 & 82 \\
\hline Un-built area ratio & 0.785 & 1.486 & 1.858 & 5.250 & 0.567 \\
\hline Energy consumption $\left(\mathrm{kWh} / \mathrm{m}^{2} /\right.$ year) & & & & 539 & 247 \\
\hline $\mathrm{CO}_{2}$ emission $(\mathrm{kg}$ per capita) & & & & 2.796 & 0.338 \\
\hline
\end{tabular}

Table 4. STVR and PVTVR ratios for measuring consumption and emissions. Source: Deakin et al. (2014).

\begin{tabular}{|l|c|c|c|c|c|c|}
\cline { 2 - 7 } \multicolumn{1}{c|}{} & LSOA 1 & LSOA 2 & LSOA 3 & LSOA 4 & LSOA 5 & Total \\
\hline Energy consumption total (kWh/p.a.) & $6,733,319$ & $14,644,009$ & $5,576,413$ & $13,140,448$ & $8,079,019$ & $48,173,208$ \\
\hline $\mathrm{CO}_{2}$ emission total (kg/p.a.) & $1,904,109$ & $4,684,583$ & $1,657,453$ & $4,002,471$ & $2,176,338$ & $14,424,954$ \\
\hline Households & 295 & 741 & 321 & 601 & 318 & 2,276 \\
\hline Energy consumption / mean household & 22,825 & 19,762 & 17,372 & 21,864 & 25,406 & \\
\hline $\mathrm{CO}_{2}$ emissions / mean household & 6,455 & 6,322 & 5,163 & 6,660 & 6,844 & \\
\hline Mean STVR & 0.59 & 0.53 & 0.53 & 0.55 & 0.56 & \\
\hline Mean PVTVR & 99.96 & 99.90 & 99.99 & 99.73 & 99.81 & \\
\hline Owner occupied & 150 & 571 & 250 & 427 & 235 & 1,633 \\
\hline Social rented & 107 & 89 & 31 & 84 & 53 & 364 \\
\hline Private rented & 38 & 81 & 40 & 90 & 30 & 279 \\
\hline
\end{tabular}

Table 5. Area-based energy consumption and $\mathrm{CO}_{2}$ emissions. Source: Deakin et al. (2014).

\begin{tabular}{l|c|c|c|c|c|}
\cline { 2 - 6 } \multicolumn{1}{c|}{} & LSOA 1 & LSOA 2 & LSOA 3 & LSOA 4 & LSOA 5 \\
\hline Current energy consumption (kWh/p.a.) & $6,733,319$ & $14,644,009$ & $5,576,413$ & $1,314,048$ & $8,079,019$ \\
\hline
\end{tabular}

Table 6. Energy savings across all LSOAs. Source: Deakin et al. (2014).

\begin{tabular}{|c|c|c|c|c|c|}
\hline & LSOA 1 & LSOA 2 & LSOA 3 & LSOA 4 & LSOA 5 \\
\hline Current $\mathrm{CO}_{2}$ emissions (kg/p.a.) & $1,904,109$ & $4,684,583$ & $1,657,453$ & $4,002,471$ & $2,176,338$ \\
\hline \multicolumn{6}{|l|}{ Retrofit(s): } \\
\hline 1. Thermal & 378,727 & 931,764 & 329,667 & 796,091 & 432,874 \\
\hline 2. Thermal-plus & 592,368 & $1,457,374$ & 515,634 & $1,245,169$ & 677,059 \\
\hline Maximum $\mathrm{CO}_{2}$ savings & 971,096 & $2,389,137$ & 845,301 & $2,041,260$ & $1,109,932$ \\
\hline
\end{tabular}

Table 7. $\mathrm{CO}_{2}$ emission reductions across all LSOAs. Source: Deakin et al. (2014).

Notes for Tables 6 \& 7

Neither the thermal, nor thermal-plus retrofit option affect the STVR and PVTVR values. This is because with mass retrofits, the only change to the urban context is infrastructural. As a result, there is no development of the building's external envelope, only to the thermography of lighting, heating and power systems, they integrate into the fabric of the buildings and occupants make use of. In this morphological structure, urban context accounts for up to $25 \%$ of the total energy consumption and $\mathrm{CO}_{2}$ emission, with mass retrofit proposals, building systems, use and occupation account for the remaining $75 \%$. These components not only offer the greatest levels of energy savings, but also the highest rates of $\mathrm{CO}_{2}$ reduction. That is energy efficiency gains, which lower the level of $\mathrm{CO}_{2}$ emission and improve the performance of these zones. 


\section{The Energy Efficient-Low Carbon Zone}

As Tables 6 and 7 indicate, the level of energy savings and reduction in the rates of $\mathrm{CO}_{2}$ emission in this energy efficient-low carbon zone are noticeable across all the LSOAs. For the thermal option, this type of retrofit results in a $25 \%$ energy saving, whereas with the thermal-plus (heat and power) option, the savings are as high as $65 \%$. Table 7 shows the thermal retrofit option to reduce the rate of $\mathrm{CO}_{2}$ emission by $25 \%$ and as much as $50 \%$ in terms of the thermal-plus option. In terms of tons per household, the thermal and thermal-plus retrofit options have the potential to reduce the emissions from 6 to 4.5 and 3 respectively.

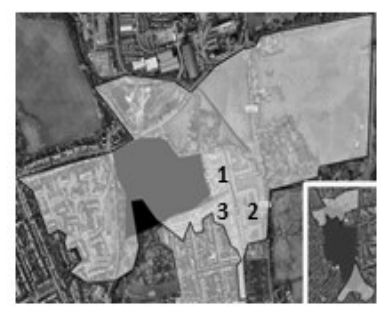

\begin{tabular}{|c|c|c|c|c|c|c|c|}
\hline \multirow[b]{2}{*}{ Type } & \multirow[b]{2}{*}{ Age } & \multirow[b]{2}{*}{$\mathrm{HA}$} & \multirow{2}{*}{$\begin{array}{c}\text { Average } \\
\text { Energy } \\
\text { Consumption } \\
\text { (kWh p.a.) }\end{array}$} & \multirow{2}{*}{$\begin{array}{c}\text { Average } \\
\mathrm{CO}^{2} \\
\text { Consumption } \\
\text { (Kg p.a.) }\end{array}$} & \multicolumn{3}{|c|}{ Tenure (\%) } \\
\hline & & & & & $\begin{array}{c}\text { Owner } \\
\text { Occupied }\end{array}$ & $\begin{array}{l}\text { Private } \\
\text { Rented }\end{array}$ & $\begin{array}{c}\text { Social } \\
\text { Rented }\end{array}$ \\
\hline 1 & $1990 \mathrm{~s}$ & 1 & 14,253 & 5,712 & 80 & 12 & 8 \\
\hline C & $1930 \mathrm{~s}$ & 2 & 20,226 & 5,712 & 29 & 15 & 56 \\
\hline$B$ & $1890-1920$ & 3 & 33,309 & 7,616 & 80 & 12 & 8 \\
\hline Total & & & 67,789 & 19,040 & & & \\
\hline Average & & & 22,596 & 6,347 & & & \\
\hline
\end{tabular}

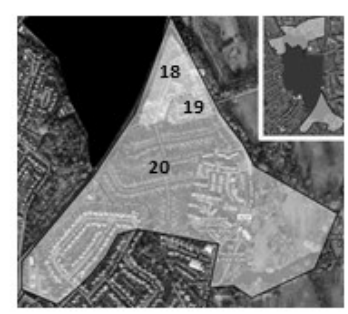

\begin{tabular}{|c|c|c|c|c|c|c|c|}
\hline \multirow[b]{2}{*}{ Type } & \multirow[b]{2}{*}{ Age } & \multirow[b]{2}{*}{$\mathrm{HA}$} & \multirow{2}{*}{$\begin{array}{c}\text { Average } \\
\text { Energy } \\
\text { Consumption } \\
\text { (kWh p.a.) }\end{array}$} & \multirow{2}{*}{$\begin{array}{c}\text { Average } \\
\mathrm{CO}^{2} \\
\text { Consumption } \\
\text { (Kg p.a.) }\end{array}$} & \multicolumn{3}{|c|}{ Tenure (\%) } \\
\hline & & & & & $\begin{array}{c}\text { Owner } \\
\text { Occupied }\end{array}$ & $\begin{array}{l}\text { Private } \\
\text { Rented }\end{array}$ & $\begin{array}{c}\text { Social } \\
\text { Rented }\end{array}$ \\
\hline$B$ & 1896-1913 & 18 & 37,972 & 9,358 & 87 & 10 & 3 \\
\hline $\mathrm{L}$ & 1990s & 19 & 16,965 & 5,440 & 87 & 10 & 3 \\
\hline $\mathrm{F}$ & Late 1930s & 20 & 25,852 & 6,964 & 85 & 3 & 12 \\
\hline Total & & & 80,789 & 21,762 & & & \\
\hline Average & & & 26,930 & 7,254 & & & \\
\hline
\end{tabular}

Table 8. Energy consumption, $\mathrm{CO}_{2}$ emissions and the structure of tenure. Source: Deakin et al. (2014)

Notes: LSOA 1 (top); LSOA 5 (bottom). "Type" refers to the housing model applied in the London Borough of Sutton's (2008) Energy Options Appraisal. "Age" refers to the approximate year of build, as designated in the Energy Options Appraisal. "HA" refers to the designated localities of similar housing stock in the Hackbridge Study, as detailed in the Energy Options Appraisal. Twenty areas of similar housing stock are used to capture housing stock within the lowestranking Lower Super Output Area (EIMD 2007) and the highest-ranking LSOA. Energy and $\mathrm{CO}_{2}$ data is from the Energy Options Appraisal. "Tenure" data is taken from the Census 2001 at Output Area level; the HA (areas of similar housing) are smaller than Output Areas therefore exact counts for each area of HA cannot be provided.

Table 8 links levels of energy consumption and $\mathrm{CO}_{2}$ emissions to the structure of tenure in the residential property sector. This draws on data profiled from LSOA's 1 and 5. These measure the most and least deprived areas. Area 1 ranks within the 21\% most deprived areas in England. Whereas Area 5 has a much lower ranking, falling within the $30 \%$ least deprived. Here it is noticeable that the social-rented sector is prevalent in Area 1. Whereas in Area 5, it is the owner-occupied and private-rented sector who dominate the housing market. This shows which tenure consumes the lowest or highest amount of energy and relationship that such levels of consumption have to $\mathrm{CO}_{2}$ emissions across the housing market. It illustrates that homes in the social-rented sector consume less energy and emit lower levels of $\mathrm{CO}_{2}$ than other housing in either the owner-occupied or private rent sector, built between 1890 and 1990.

If we summarise the potential benefits of these efficiencies in energy consumption and rates of $\mathrm{CO}_{2}$ emission, the significance of this area-based analysis becomes clear. For with the existing proposal, housing situated within the social rented sector is excluded from the retrofit, because it already commands an energy efficiency and $\mathrm{CO}_{2}$ emission rating of $75 \%$. Whereas the retrofit proposals covering the owner-occupied and private rented sectors are included for the reason that they fall below this threshold and as a result, will benefit from fabric-based improvements in energy consumption and $\mathrm{CO}_{2}$ emission. While this leaves the occupants of the social-rented sector with the status of being best in class, it not only fails to compensate them for being the "better behaved" occupants of the housing market. This is because it not only excludes them from the benefits of any improvements to the built fabric, but respective savings and reductions that would otherwise lift them out of the fuel poverty, which they experience.

The bias of this cap in favour of the owner-occupied sector and private rented tenures becomes even more noticeable in listing the potential benefits occupants of the social rented sector cannot gain access to. This is 
because for the owner-occupied sector, the mass retrofit not only provides the benefit of lower energy bills and compensation for any surplus energy fed back into the grid, but the uplift in asset values resulting from the capitalisation of such revenues as the income streams of low-carbon residential properties.

The sequencing of the mass retrofit proposal also tends to reinforce this bias. For here it is proposed the "low hanging fruit" of the thermal and thermal-plus retrofit options, should form stage 1 , with stage 2 and 3 following on from this. This means that in the first instance, the benefits of the retrofit shall be limited to the owner-occupied and private rented sectors of the housing market and will not extend into the social sector, which shall be unable to access them until completion of stages 2 and 3 . This in turn means that, for the owner-occupied and private sector, the benefits of the full $78 \%$ reduction in carbon emission may be gained over stage 1 and 2 of the retrofit, while the $28 \%$ reduction in carbon emissions, which the social rented sector benefit from, cannot be achieved until the completion of stage 2 .

Exactly how the retrofit actions planned for stage 2 and as a stage 3 demonstration of what is smart about the ESCO, peak-loading management and dynamic pricing of this cloud computing and how the loT will improve the performance of the city-district, still needs to be fully assessed. All that it is currently possible to say is "all things being equal", the projected figure of an extra $28 \%$ savings and additional reduction (forecast to be approximately $5 \%$ ) should bear down further on the levels of energy consumption and rates of $\mathrm{CO}_{2}$ emission. That is, improve performance in accordance with the socio-demographic structure, which aligns with the environmental profile of this city-district and under-grids the sustainability of the energy efficient-low carbon zones as an inclusive growth strategy.

Given the environmental profile of the city-district that currently surfaces under stage 1 is biased in overcompensating middle-to-high-income groups for their energy consumption and $\mathrm{CO}_{2}$ emission, the crosscutting nature of the digital infrastructures, data management systems and renewable energies undergridding the sustainability of stage 2 and 3 are significant. This is because together they provide the means for the energy savings and $\mathrm{CO}_{2}$ reductions surfacing from this environmental profile, to cut across the structure of the housing market and be inclusive, vis-à-vis equally accessible by low, middle and high-income groups alike. In this way (i.e. by cutting across the structure of the housing market), it is stages 2 and 3 that open up the spaces, which provide the means to redress some of the imbalances that currently underlie the social-demographic structure of the housing market. Something this under-gridding of the sustainability begins to balance out in the city-district, by making the benefits of energy efficient-low carbon zones accessible to everyone in the housing market. For only in this way, vis-à-vis by being accessible to everyone and shared equally across those in the housing market, can any proposals made to under-grid the sustainability of city-districts as efficient-low carbon zones be seen to support an inclusive growth. That is to say, support such growth, because the status of the zones this grid rests on, not only assemble the means under which to break with the legacy of the past, but for the reason they open-up the prospect of everyone in the residential property sector prospering equally from the future it offers (Deakin et al. 2014).

\section{Conclusions}

The inspiration for this paper is the potential, which the emerging literature on smart cities has to break with legacies of the Ranking System and Future Internet accounts of such developments. Break with these legacies and cast the intellectual capital of smart cities as future internet-based developments. Future internet-based developments whose digital infrastructures, data management systems and renewable energies create wealth from a regional innovation of a cloud computing driven loT.

This review of the literature serves to overcome the limitations of these legacies by capturing the metrics of those digital infrastructures, data management systems and renewable energies that bring the creation of wealth from regional innovations centre stage as the cloud computing and loT of smart cities. That cloud computing and IoT, which is smart in valuing the environmental sustainability of the energy savings and carbon reductions of city-districts, de Jong et al. (2015) indicate have until now tended to be ignored. Have tended to be ignored, because until now, the intellectual capital of smart cities has been divided. Divided as future internet-based developments, either in the digital infrastructures of data management systems, or renewable energies of regional innovations.

The critical synthesis this paper offers is based on an inter-disciplinary reading of smart cities and insights a Triple Helix inspired account of future internet-based developments offers into the informatics of that energetic, which constitute the digital infrastructures, data management systems and renewable energies of a regional innovation. In particular, that regional innovation, which covers the morphological structure of the urban extensions, infill and mass retrofits smart cities call for. 
In going on to focus attention on the metrics of the mass retrofit underway in the London Borough of Sutton, the paper also serves to demonstrate how the urban morphology of this regional innovation does matter. How the urban morphology of this regional innovation does matter for the reason that being aware of the considerable energy savings and $\mathrm{CO}_{2}$ reductions, which the cloud computing of this loT offer is not enough. For not knowing whether the distribution of costs and benefits, which under-grid the sustainability of citydistricts are spread equally, means it is impossible to say if the energy efficient-low carbon zones in question are socially just. Impossible to say if they are socially-just, because to verify this means, it is first necessary for the digital infrastructures, data management systems and renewable energies of the cloud computing, which under-grids the sustainability of the city-district as an IoT, to baseline the social-demographic structure of the housing market. Then draw upon the results of the analysis to assess whether the social baseline of this environmental profile, create the wealth needed. That wealth, which is needed for any regional innovation to not only under-grid the sustainability of this city-district, but also meet the requirement for the suburban housing market in Hackbridge to support the energy savings and reductions in carbon emissions that any energy efficient-low carbon zone, which claims to be socially just would be expected to render.

This indicates that while those smart cities who pioneer future internet-based developments do possess the digital infrastructures, data management systems and renewable energies needed, the industrial ecology of the regional innovation, which is currently in place to under-grid the sustainability of city-districts as the cloud computing of an IoT is lacking. In that sense, is lacking the levels of energy saving and reduction in $\mathrm{CO}_{2}$ emission required for the distribution of costs and benefits generated from such concrete investment opportunities in the development of energy efficient-low carbon zones to be shared equally. That is to say, to be shared equally as a standard measure of the wealth created from concrete investment opportunities in the renewable energies of a regional innovation, which is not only environmentally sustainable in terms of the city-districts this loT under-grids, but in relation to the energy efficient-low carbon zone it also renders as an ecological footprint. In particular, as an ecological footprint, which not only saves energy and reduces carbon emissions, but is also socially just. Is also socially just in terms of the inclusive growth such a post-carbon economy secures as a climate neutral adaptation strategy.

Given that cities around the world all now share the ambition to be smart in sustaining the transition to a post-carbon economy, which is climate neutral, the authors would suggest these critical insights into the reflexive instability of the intellectual capital tied up in smart cities as pioneers of future internet-based developments driving this inclusive growth strategy is significant. Is significant, because the metrics of those future internet-based developments associated with the digital infrastructures of data management systems and renewable energies they also promote as an IoT, suggest such growth generates a:

- reduction of 3 tons in the levels of $\mathrm{CO}_{2}$ emission, gained from the energetics of this regional innovation;

- further 3 tons of $\mathrm{CO}_{2}$ emission reduction sourced from the informatics of this under-gridding and the sustainability of city-districts;

- additional 5\% estimated reduction in $\mathrm{CO}_{2}$ emissions from the micro-grid underlying this energy efficient-low carbon zone;

- $\quad$ projected 6 tons reduction in $\mathrm{CO}_{2}$ emissions from this inclusive growth strategy;

- $\quad 78 \%$ overall reduction in $\mathrm{CO}_{2}$ emissions, which equates to an ecological footprint of 1.5 hectares and post-carbon economy that meets the IPCC standards of climate neutrality.

While such a climate adaptation strategy may generate a smart, sustainable and inclusive growth that has no adverse impact on global warming, $50 \%$ of the savings and reductions, which this generates, are not even across the structure of tenure in the housing market. This is because within this structure of tenure it is the social rented sector that is excluded from the benefits of the energy saving and $\mathrm{CO}_{2}$ emission reductions in the housing market, but which is still left to pick up the costs of under-gridding the sustainability of citydistricts as the energy efficient-low carbon zones of the residential property sector. It is also due to the distribution of the remaining $28 \%$ of energy savings and $\mathrm{CO}_{2}$ reductions, still being skewed in favour of the owner-occupied and private-rented sectors, as a result of the initial schedule for under-gridding the sustainability of city-districts, excluding the social sector. That is from the benefits, but not the costs, which are associated with the design and layout of energy efficient-low carbon zones supported by the web-based data collection and information processing of a smart (micro) grid.

This clearly demonstrates that contrary to what such regional innovations tend to claim about the digital infrastructures of data management systems, renewable energies do not currently offer, either the data collection, or information processing for smart (micro) grids to baseline the residential property sector as the 
inclusive growth strategy of a post-carbon economy which is climate neutral. For the infrastructures, management systems, and renewable energies they currently offer to collect data and process information from these smart (micro) grids, are not only socially divisive, but also out-of-balance with the popular demand for the environmentally sustainability of city-districts (as energy efficient-low carbon zones) to be inclusive. To be inclusive in granting the members of those neighbourhood communities who make a valuable contribution to energy efficient-low carbon zones, equal access to the proceeds of the wealth they create, but the structure of tenure in the housing market does not legally guarantee them a right to. Does not legally guarantee them a right of access to, but still expects them to bear the cost of any such exclusion as those occupants of the residential property sector left in fuel poverty.

If we are to avoid the potential such divisions have to de-stabilise such a process of regional innovation, then the structure of tenure in the housing market has to be removed as a basis to govern the distribution of wealth created from mass retrofit proposals. This means grounding the distribution of wealth created from such a regional innovation, not in the structures of tenure, but instead in the urban morphology of the sociodemographic structure retrofit proposals their inclusive growth either stand or fall on. In the urban morphology of those socio-demographic structures, which not only baseline the environmental profile of the retrofit proposal, but also under-grid the sustainability of the very city-districts that support the development of energy efficient-low carbon zones as an inclusive growth strategy. For it is only in base-lining the urban morphology of these structures, profiles and zones, that it subsequently becomes possible for the process of wealth creation to break with the limitations of the meta-stabilisations, which smart cities currently market as the attributes of digital infrastructures. Break with them and allow the data management systems of renewable energies to under-grid the value of that sustainability on which the cloud computing of this loT stand.

In that sense, stand as critical insights into the meta-stabilisations future internet-based developments pioneer. Which they pioneer, it might well be added, not only as the informatics (digital infrastructures and data management systems) of future internet developments, but energetic of a regional innovation whose creation of wealth from renewable energies currently generates inequalities in the distribution of those costs and benefits, that under-grid the sustainability of them as city-districts. Costs and benefits that if left unaccounted for might not only destabilise this regional innovation as a process of wealth creation, but also undermine, rather than under-grid the sustainability of city-districts. Undermine, rather than under-grid the sustainability of city-districts, because the savings and reductions, which energy efficient-low carbon zones generate maybe (mis)appropriated by members of the community that are not able to legitimate any socially just claim to them as the proceeds of an inclusive growth strategy. That inclusive growth strategy, which cities, nation states, the EC and the IPPC, all do much to popularize and the data collection, information processing, cloud computing and loT of smart (micro) grids, also promote as concrete investment opportunities. Be they on the grounds of their status as engineering solutions, whose renewable energies bring the built environment to the fore as concrete investment opportunities, or on the basis of that wealth, which regional innovations create to under-grid the sustainability of city-districts. To under-grid the sustainability of city-districts as the IoT of an energy efficient-low carbon zone whose inclusive growth strategy, is also resilient enough for the ecological footprint this generates to stabilise the transition towards the post-carbon economy of a climate neutral adaptation.

\section{References}

Bourdic, L. and Salat, S. (2012) Building Energy Models and Assessment Systems at the District and City Scales. Building Research and Information, vol. 40, no. 4: 518-526.

Bourdic, L., Salat, S. and Nowacki, C. (2012) Assessing Cities: A New System of Cross-Scale Spatial Indicators. Building Research and Information, vol. 40, no. 5: 592-605.

Brandt, N., Campbell, F, Deakin, M., Johansson, S., Malmström, M., Mulder, K., Pesch, U, Tatarchenko, O. and Årman, L. (2014) Technical Report: European Cities Moving Towards Climate Neutrality Participation, Indicators and Benchmarking, KTH, Stockholm.

Caragliu, A., Del Bo, C. and Nijkamp, P. (2013) Smart Cities in Europe. In: Deakin, M. (ed) Smart cities: governing, modelling and analysing the transition. Routledge, Oxon. 
de Jong, M., Joss, S., Schaven, D., Zhan, C. and Weijnen, M. (2015) Sustainable-smart-resilient-low carbon-eco-knowledge cities; making sense of a multitude of concepts promoting sustainable urbanization. Journal of Cleaner production, vol. 109: 25-38.

Deakin, M. (2011) The Embedded Intelligence of Smart Cities, International Journal of Intelligent Buildings, vol. 3, no. 2: 189-187.

Deakin, M., Campbell, F. and Reid, A. (2012a) The Mass-retrofitting of an Energy Efficient Low - Carbon Zone: Base-lining the Urban Regeneration Strategy, Vision, Master-plan and Redevelopment Scheme, Energy Policy, vol. 45: 187-200.

Deakin, M., Campbell, F. and Reid, A. (2012b) The Mass-retrofitting of an Energy Efficient Low - Carbon Zone, Energy, vol. 65, no. 4:197-208.

Deakin, M. and Leydesdorff, L. (2013) The Triple Helix of Smart Cities: A Neo-evolutionist Perspective, in Deakin, M. (ed.) Smart Cities: Governing, Modelling and Analysing the Transition, Oxford, Routledge.

Deakin, M. (ed.) (2013) Smart Cities: Governing, Modelling and Analysing the Transition, Oxford, Routledge.

Deakin, M. (2014) Smart Cities: the State-of-the-Art and Governance Challenge. Triple Helix, vol. 1, no. 1: 117.

Deakin, M., Campbell, F., Reid, A. and Orsinger, J. (2014) The Mass-Retrofitting of an Energy Efficient Low Carbon Zone, New York, Springer.

Giffinger, R., Kramar, H. and Haindl, G. (2008) The Role of Rankings in Growing City Competition. XI EURA Conference, Milan.

Hirst, P., Hummerstone, E., Webb, S., Karlsson, A. K., Blin, A. S., Duff, M., Jordanou, M. and Deakin, M. (2012). JESSICA for Smart and Sustainable Cities, European Investment Bank, Luxemburg.

Intergovernmental Panel on Climate Change (2015) Climate Change 2014: Mitigation of Climate Change (Vol. 3). Cambridge University Press.

Komninos, N., Pallot, M. and Schaffers, H. (2013) Special Issue on Smart Cities and the Future Internet in Europe. Journal of the Knowledge Economy, vol. 13, no. 2: 119-134.

Komninos, N. (2014) The Age of Intelligent Cities, Oxford: Routledge.

Kourtit, K., Deakin, M., Caragliu, A., Del Bo, C., Nijkamp, P., Lombardi, P. and Giordano, S. (2013) An advanced triple helix network framework for smart city performance, In: Deakin, M. (ed.) Smart Cities: Governing, Modelling and Analysing the Transition, Oxford, Routledge.

Lazaroiu, G.C. and Roscia, M., (2012) Definition methodology for the smart cities model. Energy, vol. 47, no 2: 326-332.

Leydesdorff, L. and Deakin, M. (2011) The Triple Helix of Smart Cities: A Neo-evolutionist Perspective. Journal of Urban Technology, vol. 18, no. 2: 53-63.

Lombardi, P. and Giordano, S. (2012) Evaluating the European Smart Cities Visions of the Future. International Journal of the Analytic Hierarchy Process, vol. 4, no. 1: 27-40.

Lombardi, P., Giordano, S., Farouh. H., and Yousef, W. (2012) Modelling the Smart City Performance. Innovation, The European Journal of Social Science Research, vol. 25, no. 2: 137-150.

London Borough of Sutton and Bioregional (2012) Hackbridge - a Zero Carbon Suburb. Available at: http://www.bioregional.com/files/publications/Hackbridge-an-area-based-strategy-for-zero-carbon-buildingsmay2012.pdf 
London Borough of Sutton (2008) Energy Options Appraisal for Domestic Buildings in Hackbridge. Produced by Parity Projects. Available at: http://www.sutton.gov.uk/CHttpHandler.ashx?id=5173\&p=0

Ratti, C., Baker, N. and Steemers, K. (2005) Energy Consumption and Urban Texture. Energy and Buildings, vol. 37, no. 7: 726-776.

Salat, S. (2009) Energy Loads, $\mathrm{CO}_{2}$ Emissions and Building Stocks: Morphologies, Typologies, Energy Systems and Behaviour, Building Research and Information, vol. 37, nos. 5-7: 589-609.

Schaffers, H., Komninos, N., Pallot, M., Trousse, B., Nilsson, M. and Oliveira, A. (2011) Smart Cities and the Future Internet: Towards Cooperation Frameworks for Open Innovation, in Domingue, J. et al. (eds.) The Future Internet: Future Internet Assembly 2011 - Achievements and Technological Promises, LNCS.

Zhang, X., Shen, G. Q., Feng, J., and Wu, Y. (2013). Delivering a low-carbon community in China:

Technology vs. strategy? Habitat international, vol. 37, 130-137.

Zhang, X. (2016). Sustainable urbanization: a bi-dimensional matrix model. Journal of Cleaner Production, vol. 134, 425-433. 